increased. This suggests that the observed memory effect is a result of an interplay between redox reactions of the ligand and the displacement of the counterions.

Despite the simplicity of the device formation demonstrated in this work, the technology proposed by Goswami and colleagues still needs to meet the grand challenges of integration and reliable operation in typical operating environments. Organic materials are prone to mechanical damage and can be sensitive to environmental conditions (moisture, light, ionizing radiation and so on). It is also difficult to form reliable electrodes, necessary for the formation of 'real' devices, on organic films. In addition, organics often suffer from ageing effects that limit their lifetime. Operation at low and high temperatures, which is expected for commercial devices, could also be an issue. All these points need to be considered and resolved to meet the demands of the memory industry. In considering where this new memristor technology might fit into emergent applications, perhaps the most obvious being neuromorphic computing, other aspects of device operation need to be examined, including their analogue programmability.

Yet the results reported in this study are sufficiently compelling to drive further work. Organic materials are compatible with flexible circuits and can be more easily tailored for biocompatibility, potentially leading to smart medical implants where bio-electronic interfaces connect to live cells. The future of this novel technology will doubtless be determined by such specific applications where incumbent technologies are unable to perform well.
Ilia Valov is at the Research Centre Jülich, Electronic Materials (PGI-7), Wilhelm-Johnen-Straße, 52425 Jülich, Germany. Michael N. Kozicki is at the School of Electrical, Computer and Energy Engineering, Arizona State University, Tempe, Arizona 85287-5706, USA. e-mail:i.valov@fz-juelich.de; michael.kozicki@asu.edu

\section{References}

1. Chua, L. Semicond. Sci. Tech. 29, 104001 (2014)

2. Waser, R. \& Aono, M. Nat. Mater. 6, 833-840 (2007)

3. Yang, J. J., Strukov, D. B. \& Stewart, D. R. Nat. Nanotech. 8, 13-24 (2013).

4. Valov, I. \& Lu, W. D. Nanoscale 8, 13828-13837 (2016)

5. Lin, W.-P., Liu, S.-J., Gong, T., Zhao, Q. \& Huang, W. Adv. Mater. 26, 570-606 (2014)

6. Hino, T., Tanaka, H., Hasegawa, T., Aono, M. \& Ogawa, T. Small 6, 1745-1748 (2010).

. Wang, H. et al. Adv. Mater. 27, 7670-7676 (2015).

8. Raeis Hosseini, N. \& Lee, J.-S. ACS Nano 9, 419-426 (2015).

9. van de Burgt, Y. et al. Nat. Mater. 16, 414-418 (2017).

10. Goswami, S. et al. Nat. Mater. 16, 1216-1224 (2017).

Published online: 23 October 2017

\title{
WHO MADE THE FIRST GLASS?
}

No other material continually exceeds itself as silica glass does. Whether it is in the stained glass of Gothic churches, the airy Crystal Palace of the Victorians or the modern skyscrapers that mirror the sky they reach towards, glass has been constantly refined to redefine its architectural possibilities. Meanwhile, in fibre composites and optical cables it challenges preconceptions about its properties and limits.

So who could not wonder when this substance first entered the palette of human-made materials? It starts to appear in archaeological remains in significant quantities in the Late Bronze Age, around $1500 \mathrm{BC}$, and consensus has long located the geographical origins in the Middle East. But that still leaves options open. Ancient Egypt used to be the obvious and default assumption, but Mesopotamia - the region mostly overlapping with present-day Iraq, with a distinct culture - has been a contender too for at least a century.

Opinion in recent decades has shifted in that direction, thanks especially to the finding of extensive glass remains in the city of Nuzi, near Kirkuk in northern Iraq, which was excavated in the 1920s and 1930s. The material culture of Nuzi is currently being re-examined in an international project $^{1}$. A new study of the Nuzi glass artefacts housed at the Harvard Semitic Museum now argues for another reconsideration of the origins of glassmaking, indicating that there is after all no compelling reason to prefer this region over Egypt ${ }^{2}$.

Shortland et al. have conducted scanning electron microscopewavelength dispersive spectroscopy (SEM-WDS) analysis to deduce the elemental compositions of the samples (which include raw glass ingots, beads and fragments of worked objects), along with measurements of strontium and neodymium isotope ratios that help to distinguish different sources of the parent silica. The results reveal that some of the artefacts are modern: introduced, presumably, by local workers during the excavation because they were paid to hand over their finds. Most of the genuine Nuzi glass is tinted blue by traces of copper; in contrast, Egyptian glass from this period shows a wider range of colorants, suggesting a more mature glassmaking technology.

The latest dating of the strata at Nuzi where most of the glass was found ${ }^{3}$ puts it pretty much contemporaneous with extensive glass remains in Egypt, in the middle of the second millennium $\mathrm{BC}$ - undermining some of the rationale for thinking the Nuzi glassmaking industry came first. True, there are also texts on glassmaking from Nineveh, the Assyrian capital in Mesopotamia, from the first millennium, which may be

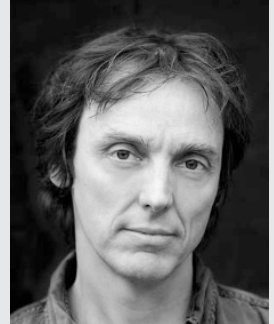

PHILIP BALL

copies of older documents, while no Egyptian records from this period have been found. But that doesn't mean Egyptians weren't making the material.

The only real reason still to prefer Nuzi over Egypt, then, would be if the former technology looked more sophisticated than the latter. But the results of Shortland et al. seem to offer no evidence of that. The Egyptian artefacts seem to be of higher quality, and moreover have a wider colour range. That too doesn't clinch the matter, but it leaves open the question of where humankind first mastered this most useful and beautiful of materials.

\section{References}

1. Shortland, A., Eremin, K., Kirk, S. \& Armstrong, J. in Materials Issues in Art and Archaeology VIII (eds Vandiver, P. B., McCarthy, B., Tykot, R. H., Ruvalcaba-Sil, J. L. \& Casadio, F.) 217-232 (MRS, 2008).

2. Shortland, A. J., Kirk, S., Eremin, K., Degryse, P. \& Walton, M. Archaeometry https://doi.org/10.1111/ arcm.12332 (2017).

3. Stein, D. L. Z. Assyriologie und Vorderasiatische Archäologie 79, 36-60 (1989). 